\title{
Plasmonics-One of the Most Prominent Journals in the Plasmonics Field in the World Today
}

\author{
Chris D. Geddes ${ }^{1}$ \\ Published online: 8 August 2019 \\ (C) Springer Science+Business Media, LLC, part of Springer Nature 2019
}

Very recently we saw the Plasmonics Journal impact factor increase to 2.926, an increase from 2.366 the year before, i.e., 2017. At this time, I'd like to thank the editorial board, all our authors/contributors, reviewers, and Springer Nature for making the Plasmonics Journal the World-wide success it is today; thank you everyone.

I recently attended the 4th International Conference on Enhanced Spectroscopies, ICES 4, in London, Canada, where during my plenary talk focused on "Plasmonic Current Generation" and its relationship to "Metal-Enhanced Fluorescence," I described how the Plasmonics field had grown significantly over the last 20 years, which has made me think about both how and why I founded the Plasmonics Journal back in the 2000s, which has subsequently precipitated this editorial.

Back in the late 1990 s early 2000 s, I got into the Plasmonics area, mostly working in what we as a community call the "Metal-Enhanced Fluorescence" or "SurfaceEnhanced Fluorescence" field today. In fact, the expression, Metal-Enhanced Fluorescence was the title of a paper I published back in 2002 [1]. Plasmonics as a discipline was very small in those days, with only a couple dozen labs around the world truly engaged in Plasmonics work and its applications. Most of the Plasmonics literature not surprisingly resided in the Physics literature: journals such as Optics Letters, Physical Review Letters, Applied Physics Letters, Journal of Physical Chemistry B publishing most of the Plasmonics material of the era. Interestingly, around the year 2000, I had noticed that a Chemistry-based Plasmonics literature had also started to significantly emerge; the great "nanoparticle" synthesis, properties, and applications work of folk like Chad Mirkin and others starting to attract a much boarder range of scientists into the Plasmonics discipline. As a Physical Chemist myself, a PhD student of Peter Douglas who was with George Porter

Chris D. Geddes

geddes@umbc.edu

1 University of Maryland Biotechnology Institute, Baltimore, MD, USA when he won the noble prize, I struggled identifying suitable journals whose journal scopes covered both the Chemistry, Physics, and Analytical aspects of Plasmonics. It was clear at that time that a new journal was needed to cover the significantly emerging area of plasmonics.

In 2005, the Annual Biophysical Society meeting was held in Long Beach, California. I was attending the meeting and had already made plans to meet the Springer editor of the Journal of Fluorescence, Aaron Johnson. I had become the editor-in-chief of the Journal of Fluorescence back in 2001. I wrote to Aaron and asked whether Springer would be open to the possibility of launching a new Journal concept I had in mind. He had replied and said that we can meet in Long Beach, where he and other Springer folk would hear my thoughts about a new journal. I had heard from other editors I knew that launching a new highprofile journal from the get-go would be very difficult, not only from a time perspective, but more importantly from getting the financial buy-in from the publisher as well as the scientific community. I subsequently set about putting a PowerPoint slide deck together about the opportunity and the real need for a highly focused journal in the Plasmonics field. I already knew a list of top faculty who would make excellent board members and back the concept. The subsequent meeting and presentation went very well, and within 2 weeks of the Long Beach meeting, we had been given the green light to launch the Plasmonics Journal from the upper Springer management. The 1st issue of Plasmonics launched in March 2006. It featured two editorials, four regular papers, one rapid communication, and an additional four regular papers dedicated to Molecular Plasmonics, solicited by Professor Wolfgang Fritzsche who also wrote an editorial on the emerging molecular Plasmonics. Page 1, Vol 1, Number 1 featured an editorial I wrote titled "Plasmonics - A vision for the future." While the journal is $100 \%$ electronic today with no printed copies, the first few volumes were additionally published in print. The photograph shows me holding one of the few copies ever printed of Volume 1, Number 1.

In addition, I have copied a list of the original Plasmonics editors and editorial board members from the inside cover of Volume 1, Number 1. Many of those folk are highly active 
plasmonics researchers today and leaders in their respective plasmonics-based discipline.

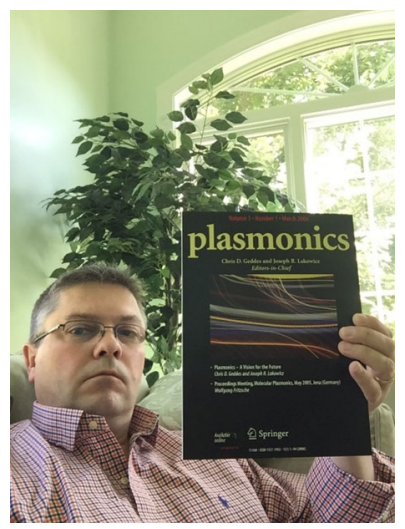

\section{PLASMONICS}

Plasmonics is an international forum for the publication of peer-reviewed leading-edge original articles that both advance and repor our knowledge base and practice of the interactions of free-metal electrons, Plasmons. Topics covered include notable advances in the theory, physics, and applications of surface plasmons in metals, to the rapidy emerging areas of bio- \& nanotechnology, biophotonics, ses. particularly welcome. Typical applications might include, but are not limited to, surface enhanced spectroscopic properties, such as Raman scattering or fluorescence, as well developments in techniques such as surface plasmon resonance and near-field scanning optical microscopy. Plasmonics publishes papers that describe new plasmonic based devices, new synthetic procedures for the preparation of nanostructures and their optical properties, as well their applications in analytical sensing. Papers describing new synthetic nications, letters to the editors, and technical and design notes. All manuscripts are subject to critical peer-review. It should be noted that the final decisions relating to manuscript suitability within Plasmonics rests solely with the editors. Plasmonics invites symposia papers to be collectively published together, through the initial consult and agreement with the editor

FOUNDING EDITOR AND EDITOR-IN-CHIEF

Chris D. Geddes, University of Maryland Biotechnology Institute, Baltimore, Maryland, USA

EDITOR-IN-CHIEF

Haryland School of Medicine

ASSISTANTS TO THE EDITORS

Administrative: Mary Y. Rosenfeld, University of Maryland School of Medicin
Scientific: Kadir Aslan, University of Maryland Biotechnology Institute

REGIONAL EDITORS FOR EUROPE

Alan G. Ryder, National Centre for Biomedical Engineering Science, National University of Ireland-Galway, Galway, Ireland

Joachim Krenn, Nano-Optics Department, Institute of Physics, Karl-Franzens-University Graz, Austria

REGIONAL EDITOR FOR ASIA

Enics Engineering, University of Tokyo, Tokyo, Japan

REGIONAL EDITOR FOR AUSTRALASIA

Paul Mulvaney, School of Chemistry, University of Melbourne, Australia

EDITORIAL BOARD

Gary A. Baker, Los Alamos National Laboratory, Los Alamos, NM

James Coe, The Ohio State University, Columbus, OH

Mostafa A. El-Sayed, Georgia Institute of Technology, Atlanta, G

Wolfgang Fritzsche, Institute for Physical High Technology, Jena, Germany

Bert Hecht, University of Basel, Basel, Switzerland
Krzysztof Kempa, Boston College, Chestnut Hill, MA

Katrin Kneipp, Harvard University Medical School, Boston, MA

Wolfgang Knoll, Max Planck Institute for Polymer Research, Mainz, Germany

Ingemar Lundstroom, IFM-Linkoping University, Linköping, Swede

Chad A. Mirkin, Northwestern University, Evanston, IL

Víctor H. Ṕrez-Luna, Illinois Institute of Technology, Chicago,

Paras N. Prasad, SUNY at Buffalo, Buffalo, NY

Thomas Schalkhammer, Universitat Wien, Wien, Austria

Din Ping Tsai, National Taiwan University, Taipel, Taiwan
Kudos to everybody for their tremendous hard work with the Plasmonics Journal over the last 13 years.

Kind regards,

Dr. Chris D. Geddes

Professor

Baltimore, Maryland, July 15th, 2019.

\section{Reference}

1. Geddes CD, Lakowicz JR (2002) Metal-enhanced fluorescence. J Fluoresc 12(2):121-129

Publisher's Note Springer Nature remains neutral with regard to jurisdictional claims in published maps and institutional affiliations. 